\title{
Comparative Numerical Study of Four Biodiesel Surrogates for Application on Diesel 0D Phenomenological Modeling
}

\author{
Claude Valery Ngayihi Abbe, ${ }^{1,2}$ Raidandi Danwe, ${ }^{1,3}$ and Robert Nzengwa $a^{1,2}$ \\ ${ }^{1}$ National Advanced School of Engineering, University of Yaounde, P.O. Box 337, Yaounde, Cameroon \\ ${ }^{2}$ Faculty of Industrial Engineering, University of Douala, P.O. Box 2701, Douala, Cameroon \\ ${ }^{3}$ Higher Institute of the Sahel, University of Maroua, P.O. Box 46, Maroua, Cameroon \\ Correspondence should be addressed to Claude Valery Ngayihi Abbe; ngayihiclaude@yahoo.fr
}

Received 19 November 2015; Revised 1 February 2016; Accepted 2 February 2016

Academic Editor: Yiguang Ju

Copyright (C) 2016 Claude Valery Ngayihi Abbe et al. This is an open access article distributed under the Creative Commons Attribution License, which permits unrestricted use, distribution, and reproduction in any medium, provided the original work is properly cited.

\begin{abstract}
To meet more stringent norms and standards concerning engine performances and emissions, engine manufacturers need to develop new technologies enhancing the nonpolluting properties of the fuels. In that sense, the testing and development of alternative fuels such as biodiesel are of great importance. Fuel testing is nowadays a matter of experimental and numerical work. Researches on diesel engine's fuel involve the use of surrogates, for which the combustion mechanisms are well known and relatively similar to the investigated fuel. Biodiesel, due to its complex molecular configuration, is still the subject of numerous investigations in that area. This study presents the comparison of four biodiesel surrogates, methyl-butanoate, ethyl-butyrate, methyl-decanoate, and methyl-9-decenoate, in a 0D phenomenological combustion model. They were investigated for in-cylinder pressure, thermal efficiency, and $\mathrm{NO}_{x}$ emissions. Experiments were performed on a six-cylinder turbocharged DI diesel engine fuelled by methyl ester (MEB) and ethyl ester (EEB) biodiesel from wasted frying oil. Results showed that, among the four surrogates, methyl butanoate presented better results for all the studied parameters. In-cylinder pressure and thermal efficiency were predicted with good accuracy by the four surrogates. $\mathrm{NO}_{x}$ emissions were well predicted for methyl butanoate but for the other three gave approximation errors over $50 \%$.
\end{abstract}

\section{Introduction}

Extensive studies regarding biodiesel combustion as an alternative for conventional diesel fuel have been performed recently $[1,2]$. Experimental studies are more and more accompanied by numerical studies to better understand the physical phenomena involved in the combustion process in diesel engines when fuelled by biodiesel [3-5]. Numerical studies in diesel combustion are often performed using surrogates for which combustion kinetic mechanisms are well established and are comparable to those of investigated fuels [6-9].

Biodiesel combustion is often found difficult to model, due to the diversity of its sources and also the complexity molecular structure of biodiesel components which consist of saturated and unsaturated fatty acid [10]. This makes the modeling procedure for such type of fuel complex. It is widely accepted that numerical simulations provide a useful tool for engine conception and optimization. It is therefore important to identify suitable biodiesel surrogates that can be used for simulation purpose.

Most of the numerical works in literature present the use of methyl butanoate and methyl decanoate [11-14] as surrogates for biodiesel fuel. These works are mostly about 1D and 3D CFD detailed combustion kinetic modeling. As it was stated in previous researches CFD modeling presents the disadvantage of a high computer cost [15]. This is where $0 \mathrm{D}$ phenomenological modeling can be effective, because it is less time-consuming.

Investigations on different biodiesel surrogates for $0 \mathrm{D}$ modeling are somehow scarce. Galle et al. [16] performed a numerical analysis of a simplified spray model for different biodiesel surrogates. Their work showed that the choice of the surrogates is of high importance, and the fuel properties are 
highly influencing the model performance. Stagni et al. [17] proposed a reduced kinetic model for biodiesel fuel for application on $0 \mathrm{D}$ model. They showed that the mechanism, when applied, permits a considerable time saving in computation.

Som et al. [18] performed four different chemical kinetic models for $0 \mathrm{D}$ and $3 \mathrm{D}$ simulation; the kinetic models were mainly based on mixture of two different set of surrogates: (a) methyl decanoate, methyl 9 decenoate, and n-heptane and (b) methyl butanoate and n-heptane. Only species mole fraction simulations were performed using 0D modeling. All the mechanisms performed very well against experimental data but at the expense of computer cost.

The objective of this study is to compare 4 different methyl and ethyl ester surrogates in strictly $0 \mathrm{D}$ phenomenological modeling for biodiesel combustion simulation purpose. The surrogates will be compared according to computed maximum pressure, $\mathrm{NO}_{x}$ emission, and thermal efficiency.

\section{Material and Methods}

2.1. OD Model Governing Equations. The model used in this study was validated in a previous study [15]; we are presenting here some fundamental relationships for a better understanding of the computing methodology.

2.1.1. Spray Submodel. Injection and spray are modeled using the theory described by Lyshevsky and Razleytsev [19-22]. The diesel jet is assumed to be constituted of two phases, an initial and a base, which are separated by a transitory characteristic length which is computed as follows:

$$
L_{b}=C_{S} d_{n} W_{e}^{0.25} M^{0.4} \rho_{l}^{-0.6},
$$

where $t_{b}=l_{b}^{2} / B_{s}$ is the characteristic time (s), $C_{s}$ is a weighing coefficient, $d_{n}$ is injector nozzle diameter, $W_{e}$ is the Webber number, and $M$ is an dimensional criterion [22].

Webber number is computed by

$$
W_{e}=\frac{U_{0}^{2} \rho_{f} d_{c}}{\sigma_{f}}
$$

where $U_{0}$ is the spray initial velocity given by

$$
U_{0}=\frac{24 q_{c} R P M}{0.75 \rho_{f} \pi d_{c}^{2} i_{c} \varphi_{\text {inj }}}
$$

$q_{c}$ is the fuel mass flow rate in $\mathrm{Kg} /$ cycle; $\rho_{f}$ is the fuel density $\mathrm{kg} / \mathrm{m}^{3} ; d_{c}$ is the injector nozzle diameter in $\mathrm{mm} ; \varphi_{\text {inj }}$ is the injection duration in crank angle degrees; $i_{c}$ is the number of injector holes.

2.1.2. Evaporation Submodel. The injected fuel is scattered into fine droplets after the transition length; these droplet are evaporating at a given rate which is proportional to their size $[20,21]$. The fuel spray is divided in two zones: In the first zone, droplets are concentrated behind the front flame area. In the second zone, droplets have reached the front flame and the evaporation is turbulent.
The size of the pulverized droplets is evaluated for each zone using the Sauter mean diameter, calculated by

$$
d_{32}=1.7 d_{n} M^{0.0733}(W e \cdot \rho)^{-0.266},
$$

where $\rho=\rho_{a} / \rho_{l}$ is the ratio of density between air and liquid fuel.

Droplets are assumed to evaporate following the $d^{2}$ law [23] for which the evaporation rate for a given droplet is

$$
d_{i}^{2}=d_{0}^{2}-K t
$$

where $d_{0}$ represents the droplet diameter after breakup (see (4)) and $d_{i}$ the diameter of the same droplet at time $t . K$ is the evaporation constant:

$$
K=10^{6} \cdot \frac{4 N_{u} D_{p} p_{s}}{\rho_{l}},
$$

where $N_{u}$ is the Nusselt number for diffusion processes, $D_{p}$ is the diffusion constant for fuel vapor, and $p_{s}$ is the fuel saturated vapor pressure.

Combustion duration, which is going to be used as an entry data for heat release rate calculation, is calculated in seconds by

$$
\tau_{\mathrm{ev}}=\frac{A_{z}}{\left(b_{i t} \lambda^{0,6}\right)},
$$

where $b_{i t}=K / d_{32}^{2}$ is the relative evaporation constant and $\lambda$ the excess air coefficient. $A_{z}$ is a fitting weighing coefficient where its value varies from 4 to 12 [21].

2.1.3. Ignition Delay and Heat Release Submodels. Ignition delay is computed using the following correlation [24]:

$$
\begin{aligned}
\mathrm{ID} & =\left[0.36+0.22 \overline{U_{p}}\right] \exp \left[E_{a} \cdot\left(\frac{1}{R T_{\mathrm{im}} \varepsilon^{n_{c}-1}}-\frac{1}{17190}\right)\right. \\
& \left.+\left(\frac{21.2}{P_{\mathrm{im}} \varepsilon^{n_{c}}-12.4}\right)^{0.63}\right],
\end{aligned}
$$

where $E_{a}$ is the fuel activation energy which is computed by $E_{a}=1310000 /(\mathrm{CN}+25), \mathrm{CN}$ is the fuel cetane number, $\overline{U_{p}}$ is the engine piston speed, $T_{\mathrm{im}}$ and $P_{\mathrm{im}}$ are, respectively, the temperature and pressure at the intake manifold, $\varepsilon$ is the engine's compression ratio, and $n_{c}$ is the polytropic exponent for compression.

The fuel burnt ratio at any crank angle $x=f(\varphi)$ is computed using a double Wiebe function $[25,26]$ by

$$
x=\beta x_{p}+(1-\beta) x_{d},
$$

where $x_{p}$ and $x_{d}$ represent the fuel burnt ratio for premixed and diffusion combustion phases and $\beta$ represents the fraction of injected fuel during premixed phase.

For each combustion phase we can write

$$
x_{i}=1-\exp \left[-a_{i}\left(\frac{\varphi-\varphi_{\mathrm{comb}}}{\Delta \varphi}\right)^{m_{i}+1}\right],
$$


where $a_{i}$ and $m_{i}$ are Wiebe weighing coefficients; $\varphi_{\text {comb }}$ is the start of ignition corresponding angle; $\Delta \varphi$ is the combustion duration in degrees of rotation.

The heat release rate is computed by derivation of $x$ about $\varphi$

2.1.4. Thermodynamic Combustion Modeling. The governing chemical reaction used in the study is given by

$$
\begin{aligned}
& \frac{\left(1-y_{r}\right)}{1+\varepsilon \phi+\omega}\left[\varepsilon \phi\left\{\mathrm{C}_{a} \mathrm{H}_{b} \mathrm{O}_{c} \mathrm{~N}_{d}+f\left(\mathrm{H}_{2} \mathrm{O}\right)\right\}+0.21 \cdot \mathrm{O}_{2}\right. \\
& \left.+0.79 \cdot \mathrm{N}_{2}+\omega \mathrm{H}_{2} \mathrm{O}\right]+y_{r}\left[y_{1}^{\prime} \mathrm{CO}_{2}+y_{2}^{\prime} \mathrm{H}_{2} \mathrm{O}\right. \\
& +y_{3}^{\prime} \mathrm{N}_{2}+y_{4}^{\prime} \mathrm{O}_{2}+y_{5}^{\prime} \mathrm{CO}+y_{6}^{\prime} \mathrm{H}_{2}+y_{7}^{\prime} \mathrm{H}+y_{8}^{\prime} \mathrm{O} \\
& \left.+y_{9}^{\prime} \mathrm{OH}+y_{10}^{\prime} \mathrm{NO}\right] \longrightarrow v_{1} \mathrm{CO}_{2}+v_{2} \mathrm{H}_{2} \mathrm{O}+v_{3} \mathrm{~N}_{2} \\
& +v_{4} \mathrm{O}_{2}+v_{5} \mathrm{CO}+v_{6} \mathrm{H}_{2}+v_{7} \mathrm{H}+v_{8} \mathrm{O}+v_{9} \mathrm{OH} \\
& +v_{10} \mathrm{NO} .
\end{aligned}
$$

The mass fraction of each species is calculated based on equilibrium assumption [27]. The following equations were exploited to determine the thermodynamic state of each surrogate of chemical formula $\mathrm{C}_{a} \mathrm{H}_{b} \mathrm{O}_{c} \mathrm{~N}_{d}$, such as specific heat, enthalpy, and entropy depending on the temperature of the combusting mixture. Consider

$$
\begin{aligned}
\frac{c_{p}}{R} & =a_{1}+a_{2} T+a_{3} T^{2}+a_{4} T^{3}+a_{5} \frac{1}{T^{2}} \\
\frac{h}{R T} & =a_{1}+\frac{a_{2}}{2} T+\frac{a_{3}}{4} T^{2}+\frac{a_{4}}{4} T^{3}+\frac{a_{5}}{5} \frac{1}{T^{2}}+a_{6} \frac{1}{T} ; \\
\frac{s}{R} & =a_{1} \ln T+a_{2} T+\frac{a_{3}}{2} T^{2}+\frac{a_{4}}{3} T^{3}+\frac{a_{5}}{4} \frac{1}{T^{2}}+a_{7} .
\end{aligned}
$$

The fitting coefficients $a_{1}$ to $a_{7}$ are the first seven Chemkin NASA coefficients of specific species in the therm.dat Chemkin file. The reduced thermodynamic data are incorporated into the code and are in compliance with the temperature range that our study is covering.

The thermodynamic tables used for air properties about temperature are taken from the Chemkin data base for temperature range of 300 to $5000 \mathrm{~K}$ [28].

The thermodynamic state of the burning mixture is calculated at each time step as a function of each species mass fraction issued from combustion products.

The molar enthalpy of the mixture is then calculated by

$$
\bar{h}=\sum y_{i} \bar{h}_{i}+\bar{h}_{f} y_{f}, \quad(\mathrm{~kJ} / \mathrm{kmol})
$$

its molar entropy is calculated by

$$
\bar{s}=\left(s_{f}-\ln y_{f}\right) y_{f}+\sum\left(s_{i}-\ln y_{i}\right) y_{i}, \quad \mathrm{~kJ} / \mathrm{kmolK} ;
$$

the heat capacity of the mixture is given by

$$
\overline{c_{p}}=c_{p_{f}} y_{f}+\sum c_{p i} y_{i}
$$

Specific volume and internal energy of the mixture are computed by

$$
\begin{aligned}
& u=h-R T, \\
& v=R \frac{T}{P},
\end{aligned}
$$

where $R$ is the universal gas constant and $h_{f}, s_{f}, c_{p f}$ are, respectively, the enthalpy, entropy, and specific of the fuel (surrogate) involved in reaction (11).

The above determined parameters with equilibrium hypothesis permit the determination of in-cylinder burning mixture pressure and temperature. The following three equations give relationships for the internal energy, specific volume, entropy, enthalpy, and specific heat with temperature and pressure as functions of the crank angle [24, 25]:

$$
\begin{aligned}
\frac{d u}{d \theta}= & \left(c_{P}-\frac{p v}{T} \frac{\partial \ln v}{\partial \ln T}\right) \frac{d T}{d \varphi} \\
& -\left(v\left(\frac{\partial \ln v}{\partial \ln T}+\frac{\partial \ln v}{\partial \ln P}\right)\right) \frac{d p}{d \varphi} ; \\
\frac{d v}{d \theta}= & \frac{v}{T} \frac{\partial \ln v}{\partial \ln T} \frac{d T}{d \varphi}-\frac{v}{p} \frac{\partial \ln v}{\partial \ln p} \frac{d p}{d \varphi} ; \\
\frac{d s}{d \theta}= & \left(\frac{c_{P}}{T}\right) \frac{d T}{d \varphi}-\frac{v}{T} \frac{\partial \ln v}{\partial \ln T} \frac{d p}{d \varphi},
\end{aligned}
$$

with $(\partial h / \partial T)_{P}=c_{P}$.

Considering the in-cylinder burning gases made of two zones (unburned and burned), variations of in-cylinder pressure and temperature about the crank angle for unburned and burned gases are given by the following relations:

$$
\begin{aligned}
\frac{d p}{d \varphi}= & \frac{A+B+C}{D+E} ; \\
\frac{d T_{b}}{d \varphi}= & \frac{-h\left(\pi b^{2} / 2+4 V / b\right) x^{1 / 2} T_{b}-T_{w}}{v m c_{P b} x} \\
& +\frac{v_{b}}{c_{P b}}\left(\frac{\partial \ln v_{b}}{\partial \ln T_{b}}\right)\left(\frac{d p}{d \varphi}\right) \\
& +\frac{h_{c u}-h_{c b}}{x c_{P b}}\left[\frac{d x}{d \varphi}-x-x^{2} \frac{C}{\omega}\right] ; \\
\frac{d T_{u}}{d \varphi}= & \frac{h\left(\pi b^{2} / 2+4 V / b\right) x^{1 / 2} T_{u}-T_{w}}{v m c_{P u} x} \\
& +\frac{v_{u}}{c_{P u}}\left(\frac{\partial \ln v_{u}}{\partial \ln T_{u}}\right)\left(\frac{d p}{d \varphi}\right) \\
& +\frac{h_{c u}-h_{c b}}{x c_{u}}\left[\frac{d x}{d \varphi}-x-x^{2} \frac{C}{\omega}\right],
\end{aligned}
$$


with

$$
\begin{aligned}
A= & \frac{1}{m}\left(\frac{d V}{d \varphi}+\frac{V C_{\text {blowby }}}{\omega}\right) ; \\
B= & h \frac{\left(d V / d \varphi+V C_{\text {blowby }} / \omega\right)}{\omega m}\left[\frac{v_{b}}{c_{P b}} \frac{\partial \ln v_{b}}{\partial \ln T_{b}} x^{1 / 2}\right. \\
& \left.\cdot \frac{T_{b}-T_{w}}{T_{b}}+\frac{v_{u}}{c_{P u}} \frac{\partial \ln v_{u}}{\partial \ln T_{u}}\left(1-x^{1 / 2}\right) \frac{T_{u}-T_{w}}{T_{u}}\right] ; \\
C= & -v_{b}-v_{u} \frac{d x}{d \varphi}-v_{b} \frac{\partial \ln v_{b}}{\partial \ln T_{b}} \frac{h_{c u}-h_{c b}}{c_{P b} T_{b}}\left[\frac{d x}{d \varphi}\right. \\
& \left.-\frac{\left(x-x^{2}\right) C_{\text {blowby }}}{\omega}\right] ; \\
D= & x\left[\frac{v_{b}^{2}}{c_{P b} T_{b}}\left(\frac{\partial \ln v_{u}}{\partial \ln T_{u}}\right)^{2}+\frac{v_{b}}{P} \frac{\partial \ln v_{b}}{\partial \ln P}\right] ; \\
E= & 1-x\left[\frac{v_{u}^{2}}{c_{P u} T_{u}}\left(\frac{\partial \ln v_{u}}{\partial \ln T_{u}}\right)^{2}+\frac{v_{u}}{p} \frac{\partial \ln v_{u}}{\partial \ln p}\right],
\end{aligned}
$$

where $h_{c b}$ and $h_{c u}$ are heat transfer coefficients to the wall, respectively, for burned and unburned zones [29]. $x$ is the fraction of burned fuel. $m$ is the fuel mass, $v$ is the specific volume, $\omega$ is the engine speed in $\mathrm{rad} / \mathrm{s}$, and $C_{\text {blowby }}$ is the blow by coefficient.

Nonlinear equations (17)-(22) are simultaneously solved using Runge-Kutta method (Dormand-Prince).

2.1.5. Nitric Oxides Emission Submodels. $\mathrm{NO}_{x}$ emissions are computed using the extended Zeldovich $[30,31]$ where $\mathrm{NO}_{x}$ formation rate is computed as

$$
\frac{d[\mathrm{NO}]}{d t}=\frac{2 C_{1}\left[1-\left([\mathrm{NO}] /[\mathrm{NO}]_{e}\right)\right]}{1+\left[[\mathrm{NO}] /[\mathrm{NO}]_{e}\right] C_{2}}
$$

where $C_{1}=K_{f, 1}[\mathrm{O}]_{e}\left[\mathrm{~N}_{2}\right]_{e}$ and

$$
C_{2}=\frac{C_{1}}{K_{r, 2}[\mathrm{NO}]_{e}[\mathrm{O}]_{e} K_{r, 3}[\mathrm{NO}]_{e}[\mathrm{H}]_{e}} ;
$$

$[X]$ is the concentration of a given species $X$ and $[X]_{e}$ the concentration of the same species at equilibrium. $K_{f, i}$ and $K_{r, 2}$, respectively, represent the forward and reverse rate of each reaction involved in the $\mathrm{NO}_{x}$ formation mechanism.

2.2. Biodiesel Surrogates. The surrogates used in this study are, respectively, methyl butanoate, ethyl butyrate, methyl decanoate, and methyl 9 decenoate. These four surrogates were chosen firstly because of the high amount of work on their combustion kinetics and study as biodiesel surrogates [33-36] and secondly for the wildly availability of their validated reduced mechanisms data. The thermodynamic data for each surrogate were taken, respectively, from the work of Liu et al. [37] for methyl butanoate, Herbinet et al. for methyl decanoate [38], Luo et al. [39] for methyl 9 decenoate, and the work of Goos et al. [40] for methyl butyrate.
TABLE 1: Engine specification [32].

\begin{tabular}{lc}
\hline Engine & 6 liters, Ford cargo \\
\hline Type & Direct injection, turbocharged \\
Number of cylinders & 6 \\
Bore $\times$ stroke $(\mathrm{mm})$ & $104.0-114.9$ \\
Compression ratio & $16.4: 1$ \\
Maximum power $(\mathrm{kW})$ & 136 at $2400 \mathrm{rpm}$ \\
Maximum brake torque $(\mathrm{Nm})$ & 650 at $1400 \mathrm{rpm}$ \\
Injection pump & In-line type \\
Injection opening pressure & 197 bar \\
\hline
\end{tabular}

TABLE 2: Fuel properties [32].

\begin{tabular}{lcc}
\hline Property & Methyl ester biodiesel & Ethyl ester biodiesel \\
\hline Density $\left(15^{\circ} \mathrm{C}\right)$ & $884.3 \mathrm{~kg} / \mathrm{m}^{3}$ & $883.4 \mathrm{~kg} / \mathrm{m}^{3}$ \\
Viscosity $\left(40^{\circ} \mathrm{C}\right)$ & $4.5 \mathrm{~mm}^{2} / \mathrm{s}$ & $4.9 \mathrm{~mm}^{2} / \mathrm{s}$ \\
Lower heating value & $37.33 \mathrm{~kJ} / \mathrm{kg}$ & $37.550 \mathrm{~kJ} / \mathrm{kg}$ \\
Cetane number & 54.9 & 53.5 \\
\hline
\end{tabular}

TABLE 3: Values of start of injection angle [32].

\begin{tabular}{lccc}
\hline \multirow{2}{*}{ Fuel } & \multicolumn{3}{c}{ Start of injection (BTDC, $\left.{ }^{\circ} \mathrm{CA}\right)$} \\
& $1100 \mathrm{rpm}$ & $1400 \mathrm{rpm}$ & $1700 \mathrm{rpm}$ \\
\hline Methyl ester biodiesel & 14 & 13 & 12 \\
Ethyl ester biodiesel & 14 & 13.25 & 12.25 \\
\hline
\end{tabular}

2.3. Engine Specification and Characteristic of the Biodiesel. The experimental analysis against which our study is about was performed by Sanli et al. [32]. Combustion and emission characteristics of a six-cylinder turbocharged DI diesel engine were investigated for methyl ester biodiesel and ethyl ester biodiesel from wasted frying oil. The characteristics of the engine are given in Table 1 and that of biodiesel fuels is given in Table 2.

The numerical study was performed for three different engine speeds for each surrogate: $1100 \mathrm{rpm}, 1400 \mathrm{rpm}$, and $1700 \mathrm{rpm}$. The injection timing for each biodiesel was in accordance with the measured start of injection angle during experimental setup; the values are given in Table 3 . The measured crank angle at which the fuel line reached the injector needle opening pressure was taken as the injection timing angle or start of injection (SOI).

The biodiesel surrogates were numerically investigated for three parameters:

(i) Maximum pressure.

(ii) $\mathrm{NO}_{x}$ emission.

(iii) Thermal efficiency.

\section{Results and Discussions}

3.1. Evaluation of Thermodynamic Properties of Biodiesel Surrogates. A first evaluation was performed for each surrogate according to (12). Equations (13) to (15) permit the computation of the mixture enthalpy, specific heat, and entropy as a function of the surrogate used. These values are used for 
TABLE 4: Comparative experimental and simulated results for methyl ester biodiesel and each surrogate at $1100 \mathrm{rpm}$.

\begin{tabular}{lccccc}
\hline RPM & & \multicolumn{2}{c}{ MEB } & & Thermal eff \\
1100 & $P_{\max }(\mathrm{Mpa})$ & Error & $\mathrm{NO}_{x}(\mathrm{ppm})$ & Error & $\mathbf{3 9 . 0 0} \%$ \\
\hline Experimental & $\mathbf{9 . 6 8}$ & & 1400 & $0.57 \%$ & $38.06 \%$ \\
(1) Methyl butanoate & 9.79 & $1.15 \%$ & 101.2 & $92.77 \%$ & $33.07 \%$ \\
(2) Ethyl butyrate & 9.10 & $5.97 \%$ & 532 & $62.00 \%$ & $34.87 \%$ \\
(3) Methyl decanoate & 9.58 & $0.98 \%$ & 142.2 & $89.84 \%$ & $33.43 \%$ \\
(4) Methyl 9 decenoate & 9.14 & $5.51 \%$ & $15.21 \%$ \\
\hline
\end{tabular}

TABLE 5: Comparative experimental and simulated results for methyl ester biodiesel and each surrogate at $1400 \mathrm{rpm}$.

\begin{tabular}{|c|c|c|c|c|c|c|}
\hline \multirow{2}{*}{$\begin{array}{l}\text { RPM } \\
1400\end{array}$} & \multicolumn{6}{|c|}{ MEB } \\
\hline & $P_{\max }(\mathrm{Mpa})$ & Error & $\mathrm{NO}_{x}(\mathrm{ppm})$ & Error & Thermal eff & Error \\
\hline Experimental & 9.89 & & 1550 & & $42 \%$ & \\
\hline (1) Methyl butanoate & 9.79 & $0.96 \%$ & 1511 & $2.52 \%$ & $41.82 \%$ & $0.43 \%$ \\
\hline (2) Ethyl butyrate & 9.09 & $8.06 \%$ & 108 & $93.03 \%$ & $36.22 \%$ & $13.76 \%$ \\
\hline (3) Methyl decanoate & 9.57 & $3.22 \%$ & 578 & $62.71 \%$ & $38.43 \%$ & $8.50 \%$ \\
\hline (4) Methyl 9 decenoate & 9.13 & $7.61 \%$ & 152.2 & $90.18 \%$ & $36.63 \%$ & $12.79 \%$ \\
\hline
\end{tabular}

TABLE 6: Comparative experimental and simulated results for methyl ester biodiesel and each surrogate at $1700 \mathrm{rpm}$.

\begin{tabular}{|c|c|c|c|c|c|c|}
\hline \multirow{2}{*}{$\begin{array}{l}\text { RPM } \\
1700 \\
\end{array}$} & \multicolumn{6}{|c|}{ MEB } \\
\hline & $P_{\max }(\mathrm{Mpa})$ & Error & $\mathrm{NO}_{x}(\mathrm{ppm})$ & Error & Thermal eff & Error \\
\hline Experimental & 9.75 & & 1525 & & $43 \%$ & \\
\hline (1) Methyl butanoate & 9.91 & $1.69 \%$ & 1782 & $16.85 \%$ & $43.66 \%$ & $1.53 \%$ \\
\hline (2) Ethyl butyrate & 9.20 & $5.57 \%$ & 128.3 & $91.59 \%$ & $37.75 \%$ & $12.21 \%$ \\
\hline (3) Methyl decanoate & 9.70 & $0.49 \%$ & 686.6 & $54.98 \%$ & $40.16 \%$ & $6.60 \%$ \\
\hline (4) Methyl 9 decenoate & 9.25 & $5.09 \%$ & 180 & $88.20 \%$ & $38.18 \%$ & $11.21 \%$ \\
\hline
\end{tabular}

the computation of the in-cylinder pressure and temperature; (21) and (22) show that in-cylinder temperature for each zone is linearly proportional to the mixture enthalpy and inversely proportional to the mixture specific heat. The variation of the mixture's entropy (19) is a nonlinear function of the temperature variation as well as the variation of in-cylinder pressure. Thus, the variation of surrogate's properties values such as enthalpy, entropy, and specific heat as a function of temperature could be a good indicator of its suitability for our OD modeling.

Figure 1 presents the variation of enthalpy against temperature for each surrogate. The curve shapes are similar and the residual values are higher for methyl butanoate and methyl 9 decenoate, with maximum difference of $36.59 \mathrm{~kJ} / \mathrm{kmol}$. Concerning entropy and specific heat (Figures 2 and 3), we also notice a similar curve shape with higher residual values between methyl butanoate and methyl decanoate, maximum values which are, respectively, of $112 \mathrm{~kJ} / \mathrm{kmolK}$ and $50.1 \mathrm{~kJ} / \mathrm{kmolK}$ for entropy and specific heat. The residuals presented in the plots are the differences between each computed parameter for each surrogate for a given temperature. The plot presents the higher residual values. These results show that some notable differences shall be expected in terms of thermodynamic computed values of combusting species during the simulation for each surrogate, which is the subject of the discussion in the next sections.

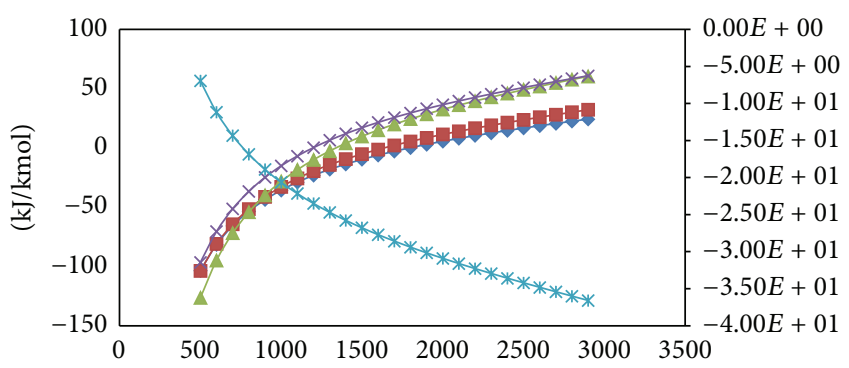

$(\mathrm{K})$
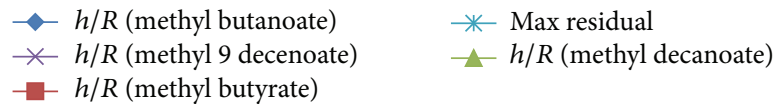

FIGURE 1: Variation of enthalpy against temperature for biodiesel surrogates.

3.2. Biodiesel Surrogates Numerical Investigation. Maximum pressure, thermal, and efficiency and $\mathrm{NO}_{x}$ emission were computed for methyl ester biodiesel and ethyl ester biodiesel from waste fried oil. The four mentioned biodiesel surrogates thermodynamic data were used in the simulation at 1100 , 1400 , and $1700 \mathrm{rpm}$. Results of simulations and subsequent error evaluations are displayed in Tables 4, 5, 6, 7, 8, and 9, respectively, at 1100, 1400, and $1700 \mathrm{rpm}$. Errors are evaluated as relative errors between measured and computed values. 
TABLE 7: Comparative experimental and simulated results for ethyl ester biodiesel and each surrogate at $1100 \mathrm{rpm}$.

\begin{tabular}{|c|c|c|c|c|c|c|}
\hline \multirow{2}{*}{$\begin{array}{l}\text { RPM } \\
1100 \\
\end{array}$} & \multicolumn{6}{|c|}{ EEB } \\
\hline & $P_{\max }(\mathrm{Mpa})$ & Error & $\mathrm{NO}_{x}(\mathrm{ppm})$ & Error & Thermal eff & Error \\
\hline Experimental & 9.86 & & 1410 & & $41 \%$ & \\
\hline (1) Methyl butanoate & 9.86 & $0.06 \%$ & 1420 & $0.71 \%$ & $38.04 \%$ & $7.22 \%$ \\
\hline (2) Ethyl butyrate & 9.16 & $7.02 \%$ & 102.3 & $92.74 \%$ & $33.07 \%$ & $19.34 \%$ \\
\hline (3) Methyl decanoate & 9.65 & $2.09 \%$ & 537 & $61.91 \%$ & $34.85 \%$ & $15.00 \%$ \\
\hline (4) Methyl 9 decenoate & 9.21 & $6.56 \%$ & 143.9 & $89.79 \%$ & $33.42 \%$ & $18.49 \%$ \\
\hline
\end{tabular}

TABLE 8: Comparative experimental and simulated results for ethyl ester biodiesel and each surrogate at $1400 \mathrm{rpm}$.

\begin{tabular}{|c|c|c|c|c|c|c|}
\hline \multirow{2}{*}{$\begin{array}{l}\text { RPM } \\
1400 \\
\end{array}$} & \multicolumn{6}{|c|}{ EEB } \\
\hline & $P_{\max }(\mathrm{Mpa})$ & Error & $\mathrm{NO}_{x}(\mathrm{ppm})$ & Error & Thermal eff & Error \\
\hline Experimental & 9.78 & & 1510 & & $42.50 \%$ & \\
\hline (1) Methyl butanoate & 9.77 & $0.04 \%$ & 1507 & $0.20 \%$ & $41.81 \%$ & $1.62 \%$ \\
\hline (2) Ethyl butyrate & 9.35 & $4.40 \%$ & 131.6 & $91.28 \%$ & $35.32 \%$ & $16.89 \%$ \\
\hline (3) Methyl decanoate & 9.84 & $0.63 \%$ & 692.3 & $54.15 \%$ & $37.42 \%$ & $11.95 \%$ \\
\hline (4) Methyl 9 decenoate & 9.39 & $3.90 \%$ & 184.9 & $87.75 \%$ & $35.70 \%$ & $16.00 \%$ \\
\hline
\end{tabular}

TABLE 9: Comparative experimental and simulated results for ethyl ester biodiesel and each surrogate at $1700 \mathrm{rpm}$.

\begin{tabular}{|c|c|c|c|c|c|c|}
\hline \multirow{2}{*}{$\begin{array}{l}\text { RPM } \\
1700 \\
\end{array}$} & \multicolumn{6}{|c|}{ EEB } \\
\hline & $P_{\max }(\mathrm{Mpa})$ & Error & $\mathrm{NO}_{x}(\mathrm{ppm})$ & Error & Thermal eff & Error \\
\hline Experimental & 9.7 & & 1500 & & $43.50 \%$ & \\
\hline (1) Methyl butanoate & 9.96 & $2.73 \%$ & 1659 & $10.60 \%$ & $44.29 \%$ & $1.82 \%$ \\
\hline (2) Ethyl butyrate & 9.47 & $2.34 \%$ & 158 & $89.47 \%$ & $36.93 \%$ & $15.10 \%$ \\
\hline (3) Methyl decanoate & 9.98 & $2.89 \%$ & 831 & $44.60 \%$ & $39.24 \%$ & $9.79 \%$ \\
\hline (4) Methyl 9 decenoate & 9.52 & $1.86 \%$ & 221.9 & $85.21 \%$ & $37.35 \%$ & $14.14 \%$ \\
\hline
\end{tabular}

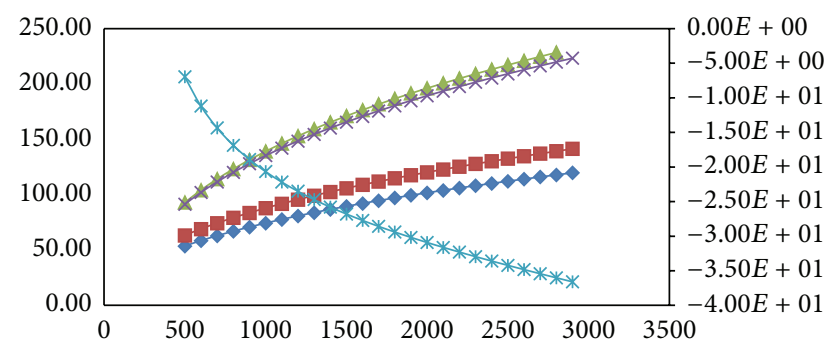

(K)

$$
\begin{aligned}
& \multimap s / R \text { (methyl butanoate) } \quad \rightarrow s / R \text { (methyl butyrate) } \\
& \neg s / R \text { (methyl decanoate) } \quad \nVdash s / R \text { (methyl } 9 \text { decenoate) } \\
& \rightarrow \text { Max residual }
\end{aligned}
$$

FIGURE 2: Variation of entropy against temperature for biodiesel surrogates.

\subsubsection{Methyl Ester Biodiesel Numerical Investigation}

Maximum in-Cylinder Pressure. Maximum pressure is fairly well predicted for each surrogate. However methyl butanoate shows a better prediction rate of an average of $1.27 \%$ accuracy across the different rpm. The other surrogates present an average accuracy of $6.53 \%, 1.56 \%$, and $6.07 \%$ for ethyl butyrate, methyl decanoate, and methyl 9 decenoate, respectively. In Figure 4 it can be seen that experimental and simulated

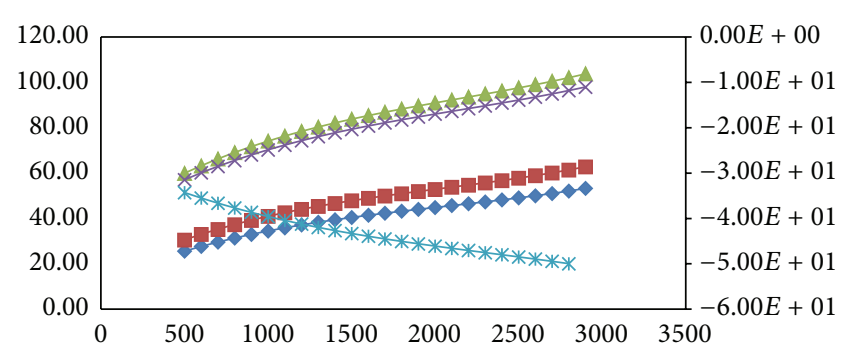

(K)

$$
\begin{aligned}
& \rightarrow c_{p} / R \text { (methyl butanoate) } \rightarrow c_{p} / R \text { (methyl butyrate) } \\
& \leftarrow c_{p} / R \text { (methyl decanoate) } \quad \times c_{p} / R \text { (methyl } 9 \text { decenoate) } \\
& \text { * Max residual }
\end{aligned}
$$

FIGURE 3: Variation of specific against temperature for biodiesel surrogates.

pressure traces closely match for each biodiesel surrogates compared to MEB experimental data. Better pressure simulations are achieved by methyl butanoate and methyl decanoate compared to the other two.

Thermal Efficiency. Thermal efficiency provides a good insight of fuel heat input to mechanical energy output during combustion cycle, especially when evaluating alternative fuel $[41,42]$. The simulation results show that methyl butanoate 


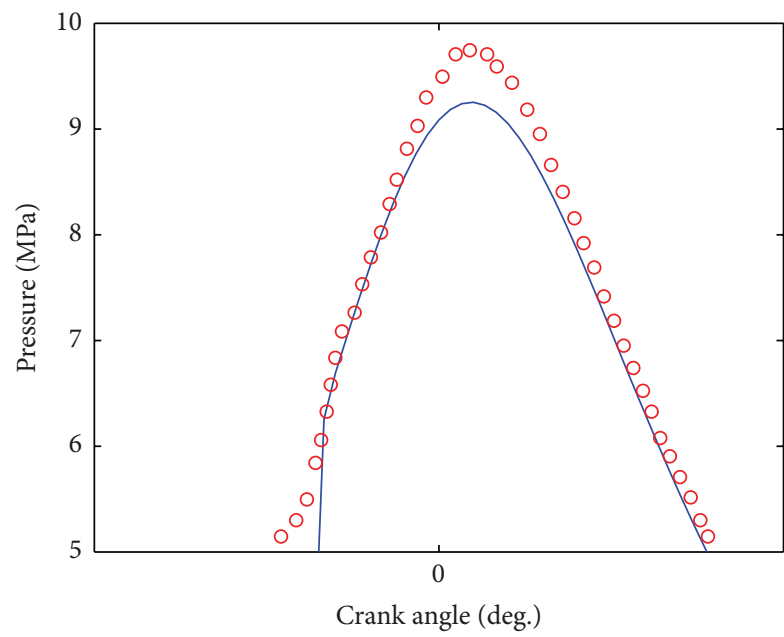

(a) Methyl 9 decenoate

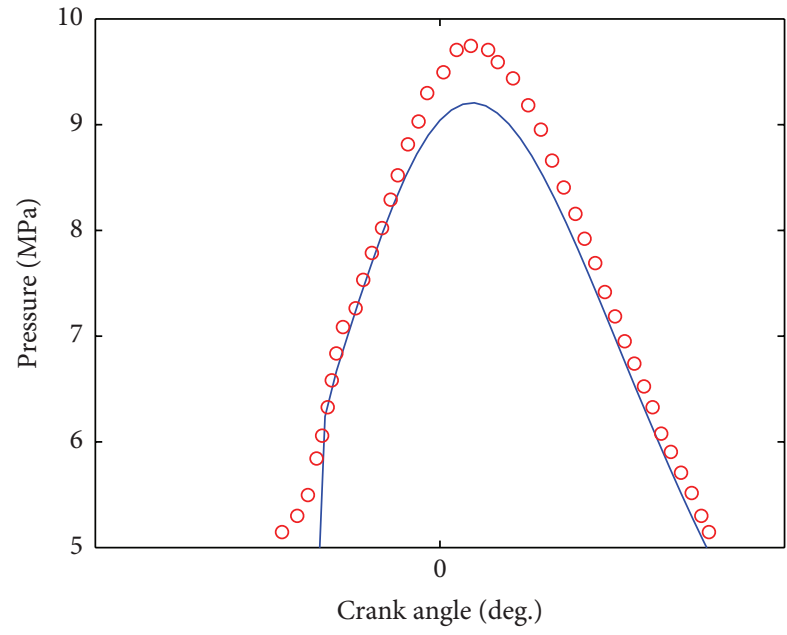

(c) Ethyl butyrate

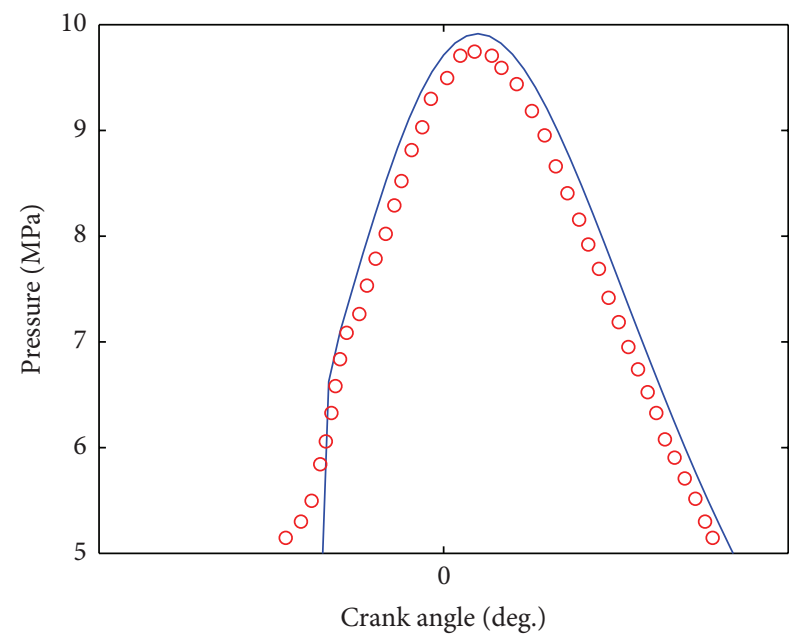

(b) Methyl butanoate

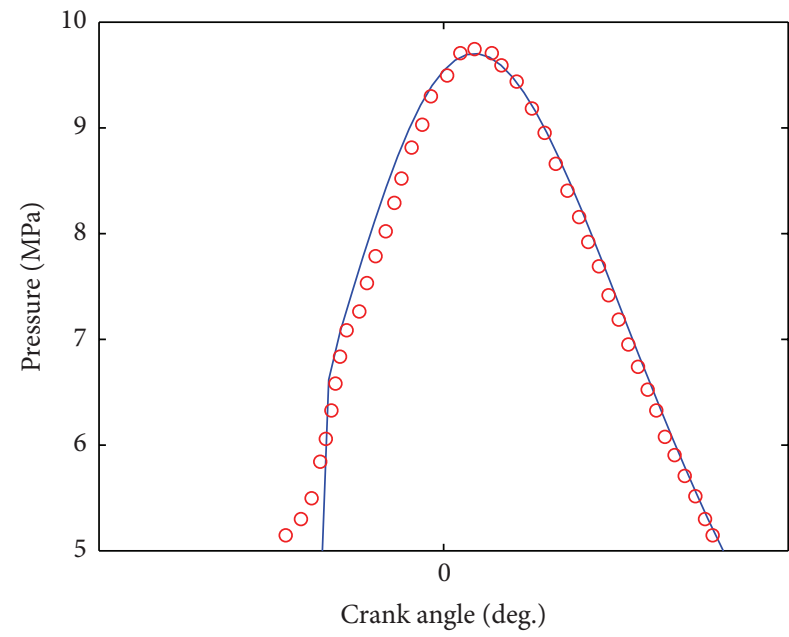

(d) Methyl decanoate

FIGURE 4: Experimental and simulated pressure trace at 1700 RPM for MEB for each surrogate.

gives the better approximation with an average error of $1.46 \%$. Ethyl butyrate, methyl decanoate, and methyl 9 decenoate present average errors below $15 \%$, which are acceptable for engine simulation. Methyl decanoate presents an approximation of average $8.56 \%$, followed by methyl 9 decenoate at $12.76 \%$ and ethyl butyrate at $13.76 \%$.

$N O_{x}$ Emissions. $\mathrm{NO}_{x}$ emissions are simulated using the extended Zeldovich mechanism [30, 43]; the simulation results present a good agreement with experimental results from methyl butanoate with an average of $6.65 \%$ error across the three regimes. Methyl decanoate, methyl 9 decenoate, and ethyl butyrate however poorly predict $\mathrm{NO}_{x}$ emissions with respective average errors of $59.9 \%, 92.46 \%$, and $89.49 \%$.

\subsubsection{Ethyl Ester Biodiesel Numerical Investigation}

Maximum in-Cylinder Pressure. Maximum pressure was calculated through simulation in the $0 \mathrm{D}$ phenomenological model, as well as in the case of methyl ester biodiesel.
Maximum pressure is also fairly well predicted for each surrogate. Methyl butanoate shows a better prediction rate of an average of $0.94 \%$ accuracy across the different rpm, which is slightly better than during the methyl ester biodiesel simulation. Simulations present an average accuracy of $4.59 \%, 1.87 \%$, and $4.10 \%$ for ethyl butyrate, methyl decanoate, and methyl 9 decenoate, respectively. Figure 5 shows that experimental and simulated pressure traces closely match for each biodiesel surrogate compared to EEB experimental data. Better pressure simulations are achieved by methyl butanoate and methyl decanoate compared to the other two, just as in the case of MEB.

Thermal Efficiency. The simulation results present a better approximation for methyl butanoate with an average error of $3.55 \%$. Ethyl butyrate, methyl decanoate, and methyl 9 decenoate present average errors close and over $15 \%$, which is below acceptable for engine simulation. Methyl decanoate presents an approximation of average $12.25 \%$, followed by methyl 9 decenoate at $16.21 \%$ and ethyl butyrate at $17.11 \%$. 


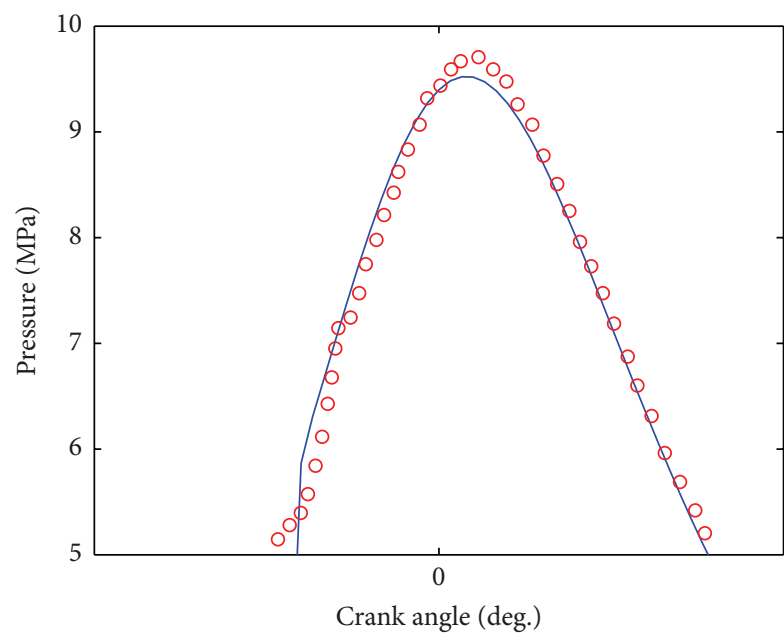

(a) Methyl 9 decenoate

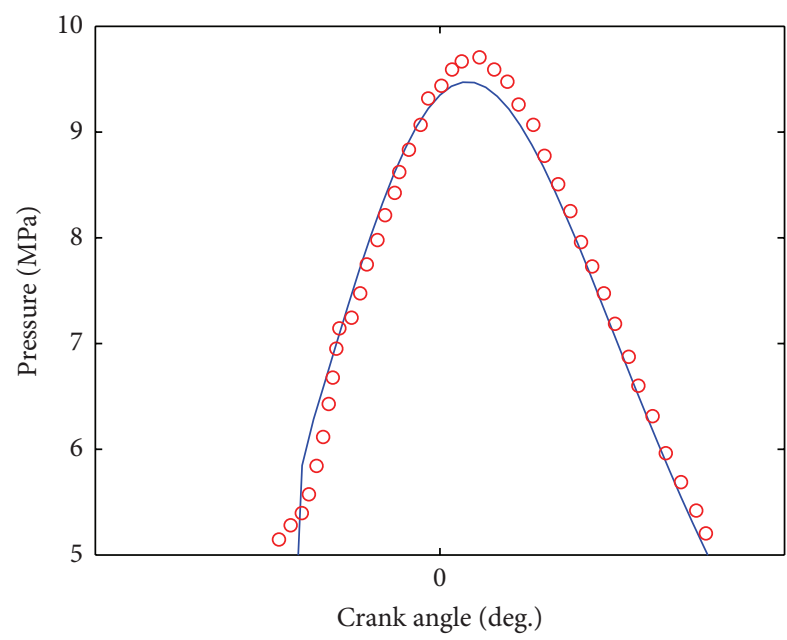

(c) Ethyl butyrate

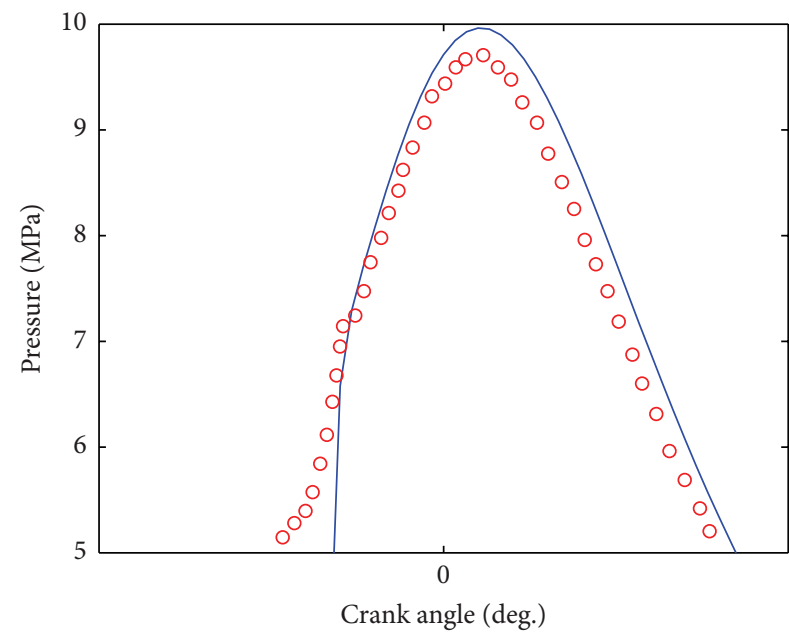

(b) Methyl butanoate

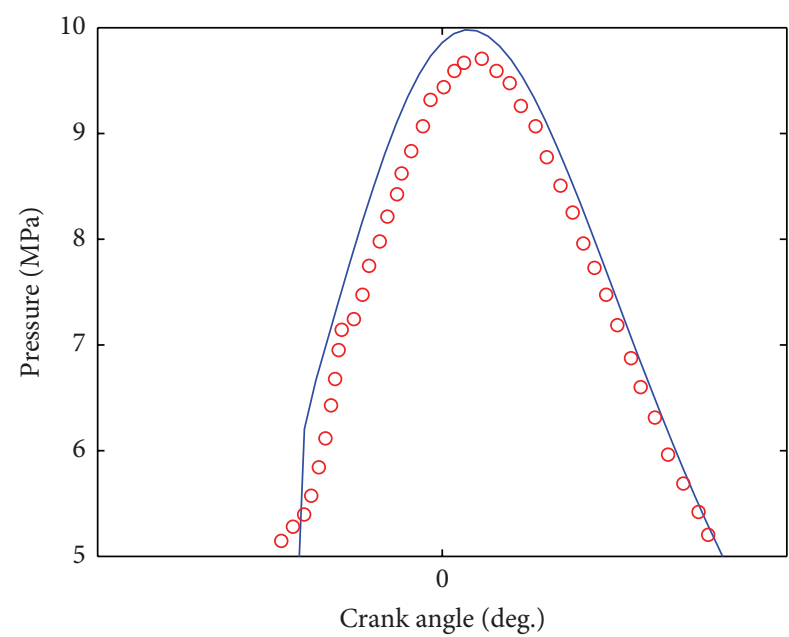

(d) Methyl decanoate

FIGURE 5: Experimental and simulated pressure trace at 1700 RPM for EEB for each surrogate.

$N O_{x}$ Emissions. As it was the case for MEB, the simulation results present a good agreement with experimental results from methyl butanoate with an average of 3.84\% error across the three regimes, which is an improvement compared to MEB simulation. Methyl decanoate, methyl 9 decenoate, and ethyl butyrate, just as it was the case for MEB, poorly predict $\mathrm{NO}_{x}$ emissions with respective average errors of $53.56 \%$, $87.59 \%$, and $91.17 \%$.

3.3. Discussion. The approximations results are similar, whether we are investigating methyl ester biodiesel or ethyl ester biodiesel. For each case, pressure trace and thermal efficiency are fairly well predicted. Ethyl butyrate and methyl 9 decenoate present the worst results in terms of simulation precision.

The overall trend observed from the various simulation results is that methyl butanoate gives better predictions of engine parameters compared to other surrogates; this is in accordance with its high rate of usage as a surrogate for biodiesel in 3D and 1D simulation studies $[4,5,44]$. However, this result is somehow contradictory with comments from Brakora et al. [45] and Hakka et al. [33] that say that methyl butanoate is not a particular good surrogate for biodiesel. While this was explained by the fact that methyl butanoate possesses a short alkylic chain and therefore cannot adequately capture ignition delay and species history, it should be noted that most of these findings were done under 3D or experimental investigations. Our 0D model only uses Chemkin Nasa coefficients to compute in-cylinder thermodynamic parameters; the ignition delay is computed as a function of the investigated biodiesel cetane number. The reaction kinetic in our model is therefore independent of the surrogate thermodynamic data.

The three other surrogates present overall good approximation for thermal efficiency and maximum pressure. Methyl decanoate presents better simulation approximation errors than ethyl butyrate and methyl 9 decenoate; that trend is interesting since one would have expected a closer approximation value for ethyl butyrate since its enthalpy, heat capacity, and entropy curves are closer to the ones for methyl 
butanoate. However, it has been noticed in the literature that methyl decanoate has been extensively used as a surrogate for biodiesel combustion simulation as compared to ethyl butyrate and methyl 9 decanoate $[13,46,47]$.

Another trend observed is the poorly predicted $\mathrm{NO}_{x}$ emission simulation for methyl decanoate, ethyl butyrate, and methyl 9 decenoate. For these three surrogates, $\mathrm{NO}_{x}$ emissions are underpredicted compared to experimental results. An earlier study, performed on Kiva-2 showed that surrogates with lesser content of oxygen tend to predict lower $\mathrm{NO}_{x}$ emission concentration [48]. In our case, each surrogate presents 2 atoms of oxygen in its formula; methyl butanoate presents a chemical formula of $\mathrm{C}_{5} \mathrm{H}_{10} \mathrm{O}_{2}$, ethyl butyrate of $\mathrm{C}_{6} \mathrm{H}_{12} \mathrm{O}_{2}$, methyl decanoate of $\mathrm{C}_{11} \mathrm{H}_{22} \mathrm{O}_{2}$, and methyl 9 decenoate $\mathrm{C}_{11} \mathrm{H}_{20} \mathrm{O}_{2}$. The stoichiometric air/fuel ratio which is calculated by $L=((8 / 3) a+8 \cdot b-c) / 0.232$ for each surrogate of formula $\mathrm{C}_{a} \mathrm{H}_{b} \mathrm{O}_{c} \mathrm{~N}_{d}$ will be, respectively, 8.788, 9.4928, 11.37, and 11.24. According to experimental parameters, the same mass of injected fuel was considered for each surrogate in the simulation. The model takes into account the molar fraction of each species contained in the surrogate. The composition of the burning mixture will therefore be dependable of the surrogate composition. The model will therefore predict a richer mixture during combustion for methyl butanoate, while others will be leaner. That could influence the calculation of oxygen content in the burning mixture and therefore will impact the computation of $\mathrm{NO}_{x}$ emission through the extended Zeldovich mechanism. Another area of investigation could be the extension of the thermodynamic data for each surrogate by integration of more chain reactions into the reduced chemical mechanical mechanism. That could lead to an increase of computation time.

\section{Conclusion}

Four biodiesel surrogates were investigated for their performance in $0 \mathrm{D}$ phenomenological combustion modeling. The surrogated thermodynamic data were those of butanoate, ethyl butyrate, methyl decanoate, and methyl 9 decenoate. Simulations were compared against experimental data gathered from the combustion of ethyl ester and methyl ester biodiesel from waste cooking oil in a 6-cylinder DI diesel engine at engine speed varying to 1100,1400 , and $1700 \mathrm{rpm}$. Each biodiesel surrogate was investigated for in-cylinder pressure, maximum pressure, thermal efficiency, and $\mathrm{NO}_{x}$ emissions. After the analysis of the simulation, the following conclusions could be derived:

(i) Enthalpy, entropy, and heat capacity of the surrogates follow similar curve shapes; the highest differences were identified for methyl butanoate and methyl decanoate concerning entropy and heat capacity and between methyl butanoate and methyl 9 decenoate for enthalpy.

(ii) Each surrogate fairly well predicted maximum pressure and thermal efficiency for each engine regime and each biodiesel.

(iii) Methyl butanoate showed the best accuracy for all three simulated parameters, $1.27 \%$ and $0.94 \%$ for maximum pressure, $1.46 \%$ and $3.55 \%$ for thermal efficiency, and $6.65 \%$ and $3.84 \%$ for $\mathrm{NO}_{x}$ emissions for $\mathrm{MEB}$ and $\mathrm{EEB}$, respectively, followed by methyl decanoate, methyl 9 decenoate, and ethyl butyrate.

(iv) Out of the four surrogates, only methyl butanoate, could well predict $\mathrm{NO}_{x}$ emissions at $6.65 \%$ and $3.84 \%$ for MEB and EEB, respectively; the other three surrogates presented heavy average errors higher than $50 \%$.

\section{Conflict of Interests}

The authors declare that there is no conflict of interests regarding the publication of this paper.

\section{Acknowledgment}

The authors are grateful to the Ministry of Higher Education of Cameroon for financing this research.

\section{References}

[1] S. A. Basha, K. R. Gopal, and S. Jebaraj, "A review on biodiesel production, combustion, emissions and performance," Renewable and Sustainable Energy Reviews, vol. 13, no. 6-7, pp. 16281634, 2009.

[2] N. Usta, E. Öztürk, Ö. Can et al., "Combustion of bioDiesel fuel produced from hazelnut soapstock/waste sunflower oil mixture in a Diesel engine," Energy Conversion and Management, vol. 46, no. 5, pp. 741-755, 2005.

[3] X. Wang, K. Li, and W. Su, "Experimental and numerical investigations on internal flow characteristics of diesel nozzle under real fuel injection conditions," Experimental Thermal and Fluid Science, vol. 42, pp. 204-211, 2012.

[4] J. Yang, M. Johansson, C. Naik et al., "3D CFD modeling of a biodiesel-fueled diesel engine based on a detailed chemical mechanism," SAE Technical Paper 2012-01-0151, SAE International, 2012.

[5] S. Som and D. E. Longman, "Numerical study comparing the combustion and emission characteristics of biodiesel to petrodiesel," Energy and Fuels, vol. 25, no. 4, pp. 1373-1386, 2011.

[6] N. Samec, B. Kegl, and R. W. Dibble, "Numerical and experimental study of water/oil emulsified fuel combustion in a diesel engine," Fuel, vol. 81, no. 16, pp. 2035-2044, 2002.

[7] H. J. Curran, P. Gaffuri, W. J. Pitz, and C. K. Westbrook, "A comprehensive modeling study of n-heptane oxidation," Combustion and Flame, vol. 114, no. 1-2, pp. 149-177, 1998.

[8] S. Hong, M. S. Wooldridge, H. G. Im, D. N. Assanis, and H. Pitsch, "Development and application of a comprehensive soot model for 3D CFD reacting flow studies in a diesel engine," Combustion and Flame, vol. 143, no. 1-2, pp. 11-26, 2005.

[9] G. Vourliotakis, D. I. Kolaitis, and M. A. Founti, "Development and parametric evaluation of a tabulated chemistry tool for the simulation of $\mathrm{n}$-heptane low-temperature oxidation and autoignition phenomena," Journal of Combustion, vol. 2014, Article ID 237049, 13 pages, 2014.

[10] L. Coniglio, H. Bennadji, P. A. Glaude, O. Herbinet, and F. Billaud, "Combustion chemical kinetics of biodiesel and related compounds (methyl and ethyl esters): experiments 
and modeling-advances and future refinements," Progress in Energy and Combustion Science, vol. 39, no. 4, pp. 340-382, 2013.

[11] S. Um and S. W. Park, "Modeling effect of the biodiesel mixing ratio on combustion and emission characteristics using a reduced mechanism of methyl butanoate," Fuel, vol. 89, no. 7, pp. 1415-1421, 2010.

[12] J. Y. W. Lai, K. C. Lin, and A. Violi, "Biodiesel combustion: advances in chemical kinetic modeling," Progress in Energy and Combustion Science, vol. 37, no. 1, pp. 1-14, 2011.

[13] P. Diévart, S. H. Won, S. Dooley, F. L. Dryer, and Y. Ju, "A kinetic model for methyl decanoate combustion," Combustion and Flame, vol. 159, no. 5, pp. 1793-1805, 2012.

[14] V. I. Golovitchev and J. Yang, "Construction of combustion models for rapeseed methyl ester bio-diesel fuel for internal combustion engine applications," Biotechnology Advances, vol. 27, no. 5, pp. 641-655, 2009.

[15] C. V. Ngayihi Abbe, R. Nzengwa, R. Danwe, Z. M. Ayissi, and M. Obonou, "A study on the 0D phenomenological model for diesel engine simulation: application to combustion of Neem methyl esther biodiesel," Energy Conversion and Management, vol. 89, pp. 568-576, 2015.

[16] J. Galle, R. Verschaeren, and S. Verhelst, "The behavior of a simplified spray model for different diesel and bio-diesel surrogates," SAE Technical Paper 2015-01-0950, 2015.

[17] A. Stagni, C. Saggese, M. Bissoli et al., "Reduced kinetic model of biodiesel fuel combustion," Chemical Engineering Transactions, vol. 37, pp. 877-882, 2014.

[18] S. Som, W. Liu, and D. E. Longman, "Comparison of different chemical kinetic models for biodiesel combustion," in Proceedings of the Internal Combustion Engine Division Fall Technical Conference (ASME '13), American Society of Mechanical Engineers, Dearborn, Mich, USA, October 2013.

[19] A. S. Lyshevsky, Fuel Atomization in Marine Diesels, Machgiz, Leningrad, Russia, 1971 (Russian).

[20] N. F. Razleytsev, Combustion Simulation and Optimization in Diesels, Vischa Shkola, Kharkiv, Ukraine, 1980 (Russian).

[21] F. I. Abramchuk, A. P. Marchenko, N. F. Razlejtsev, and E. I. Tretiak, Modern Diesel Engines: Increase of Fuel Economy and Durability, Technika, Kiev, Ukraine, 1992.

[22] A. S. Kuleshov, "Multi-zone DI diesel spray combustion model for thermodynamic simulation of engine with PCCI and high EGR level,' SAE International Journal of Engines, vol. 2, no. 1, pp. 1811-1834, 2009.

[23] D. B. Spalding, "The combustion of liquid fuels," in Proceedings of the Fourth Symposium (International) on Combustion and Detonation Waves, The Combustion Institute, Cambridge, Mass, USA, 1953.

[24] Y. Aghav, V. Thatte, M. Kumar et al., "Predicting ignition delay and $\mathrm{HC}$ emission for DI diesel engine encompassing EGR and oxygenated fuels," SAE Technical Paper 2008-28-0050, SAE, 2008.

[25] N. Watson, A. Pilley, and M. Marzouk, "A combustion correlation for diesel engine simulation,” SAE Technical Paper 800029, 1980.

[26] O. Grondin, Modélisation du moteur à allumage par compression dans la perspective du contrôle et du diagnostic [Ph.D. thesis], Université de Rouen, Rouen, France, 2004.

[27] C. R. Ferguson and T. K. Allan, Internal Combustion Engines: Applied Thermosciences, John Wiley \& Sons, Hoboken, NJ, USA, 2nd edition, 2000.
[28] R. J. Kee, F. M. Rupley, and J. A. Miller, "The chemkin thermodynamic data base," Tech. Rep., 1990.

[29] G. Woschni, "A universally applicable equation for the instantaneous heat transfer coefficient in the internal conbustion engine," SAE Technical Paper 670931, 1967.

[30] J. B. Heywood, Internal Combustion Engine Fundamentals, McGraw-Hill, New York, NY, USA, 1988.

[31] G. A. Lavoie, J. B. Heywood, and J. C. Keck, "Experimental and theoretical study of nitric oxide formation in internal combustion engines," Combustion Science and Technology, vol. 1, no. 4, pp. 313-326, 1970.

[32] H. Sanli, M. Canakcib, E. Alptekinb, A. Turkcanb, and A. N. Ozsezenb, "Effects of waste frying oil based methyl and ethyl ester biodiesel fuels on the performance, combustion and emission characteristics of a DI diesel engine," Fuel, vol. 159, pp. 179-187, 2015.

[33] M. H. Hakka, P.-A. Glaude, O. Herbinet, and F. Battin-Leclerc, "Experimental study of the oxidation of large surrogates for diesel and biodiesel fuels," Combustion and Flame, vol. 156, no. 11, pp. 2129-2144, 2009.

[34] W. Wang and M. A. Oehlschlaeger, "A shock tube study of methyl decanoate autoignition at elevated pressures," Combustion and Flame, vol. 159, no. 2, pp. 476-481, 2012.

[35] S. Zhang, L. J. Broadbelt, I. P. Androulakis, and M. G. Ierapetritou, "Comparison of biodiesel performance based on HCCI engine simulation using detailed mechanism with on-the-fly reduction," Energy \& Fuels, vol. 26, no. 2, pp. 976-983, 2012.

[36] A. M. El-Nahas, M. V. Navarro, J. M. Simmie et al., "Enthalpies of formation, bond dissociation energies and reaction paths for the decomposition of model biofuels: ethyl propanoate and methyl butanoate," The Journal of Physical Chemistry A, vol. 111, no. 19, pp. 3727-3739, 2007.

[37] W. Liu, R. Sivaramakrishnan, M. J. Davis, S. Som, D. E. Longman, and T. F. Lu, "Development of a reduced biodiesel surrogate model for compression ignition engine modeling," Proceedings of the Combustion Institute, vol. 34, no. 1, pp. 401409, 2013.

[38] O. Herbinet, W. J. Pitz, and C. K. Westbrook, "Detailed chemical kinetic mechanism for the oxidation of biodiesel fuels blend surrogate," Combustion and Flame, vol. 157, no. 5, pp. 893-908, 2010.

[39] Z. Luo, M. Plomer, T. Lu et al., "A reduced mechanism for biodiesel surrogates for compression ignition engine applications," Fuel, vol. 99, pp. 143-153, 2012.

[40] E. Goos, A. Burcat, and B. Ruscic, "Transfer of extended third millennium ideal gas and condensed phase thermochemical database," in Extended Third Millennium Ideal Gas and Condensed Phase Thermochemical Database, Engineering FOA, Haifa, Israel, 2009.

[41] G. Labeckas and S. Slavinskas, "The effect of rapeseed oil methyl ester on direct injection Diesel engine performance and exhaust emissions," Energy Conversion and Management, vol. 47, no. 1314, pp. 1954-1967, 2006.

[42] C. D. Rakopoulos, K. A. Antonopoulos, D. C. Rakopoulos, D. T. Hountalas, and E. G. Giakoumis, "Comparative performance and emissions study of a direct injection Diesel engine using blends of Diesel fuel with vegetable oils or bio-diesels of various origins," Energy Conversion and Management, vol. 47, no. 18-19, pp. 3272-3287, 2006.

[43] G. A. Lavoie and P. N. Blumberg, "A Fundamental model for predicting fuel consumption, $\mathrm{NO}_{x}$ and $\mathrm{HC}$ emissions of the 
conventional spark-ignition engine," Combustion Science and Technology, vol. 21, no. 5-6, pp. 225-258, 1980.

[44] I. Uryga-Bugajska, M. Pourkashanian, D. Borman, E. Catalanotti, and C. W. Wilson, "Theoretical investigation of the performance of alternative aviation fuels in an aero-engine combustion chamber," Proceedings of the Institution of Mechanical Engineers, Part G: Journal of Aerospace Engineering, vol. 225, no. 8, pp. 874-885, 2011.

[45] J. L. Brakora, Y. Ra, and R. D. Reitz, "Combustion model for biodiesel-fueled engine simulations using realistic chemistry and physical properties," SAE International Journal of Engines, vol. 4, no. 1, pp. 931-947, 2011.

[46] K. Seshadri, T. Lu, O. Herbinet et al., "Experimental and kinetic modeling study of extinction and ignition of methyl decanoate in laminar non-premixed flows," Proceedings of the Combustion Institute, vol. 32, no. 1, pp. 1067-1074, 2009.

[47] S. M. Sarathy, M. J. Thomson, W. J. Pitz, and T. Lu, "An experimental and kinetic modeling study of methyl decanoate combustion," Proceedings of the Combustion Institute, vol. 33, no. 1, pp. 399-405, 2011.

[48] C. Y. Choi and R. D. Reitz, "Modeling the effects of oxygenated fuels and split injections on DI diesel engine performance and emissions," Combustion Science and Technology, vol. 159, no. 1, pp. 169-198, 2000. 


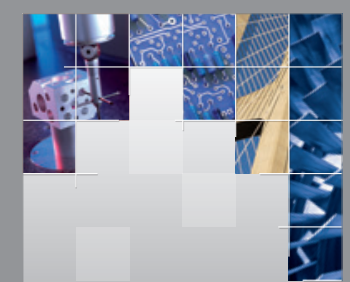

\section{Enfincering}
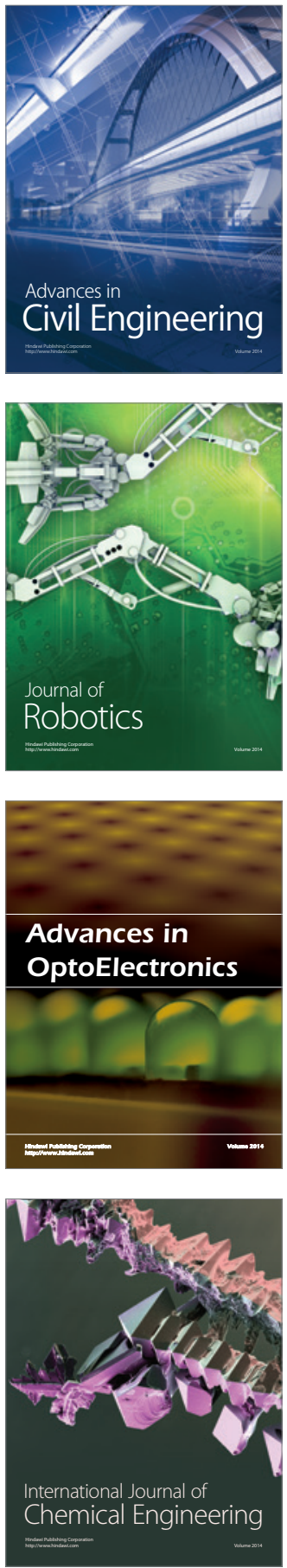

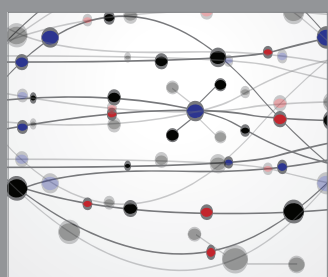

The Scientific World Journal

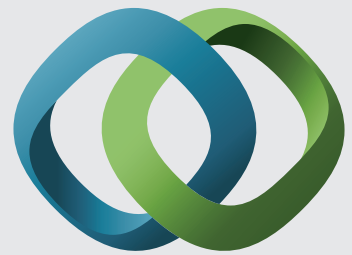

\section{Hindawi}

Submit your manuscripts at

http://www.hindawi.com
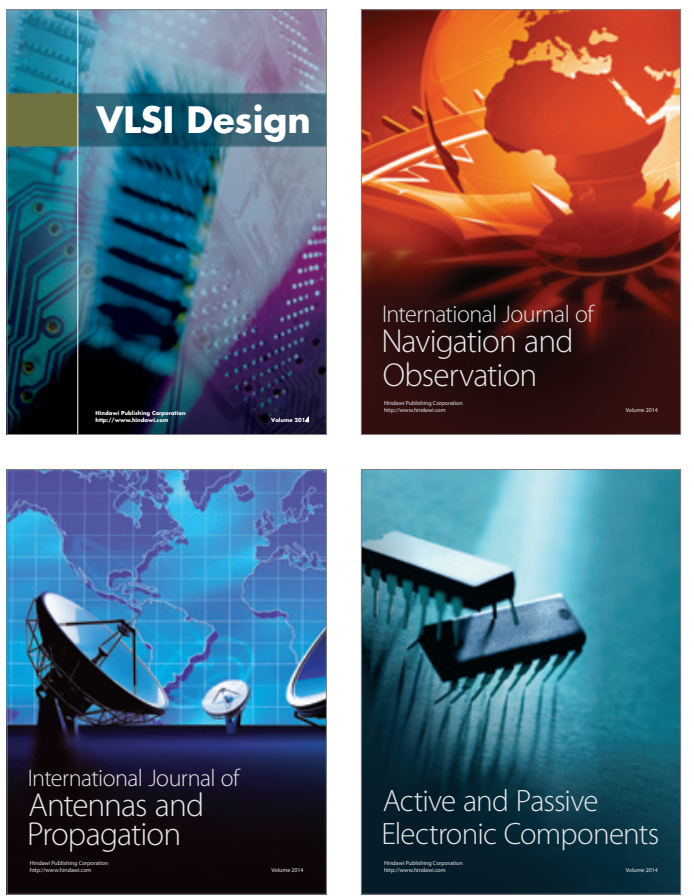
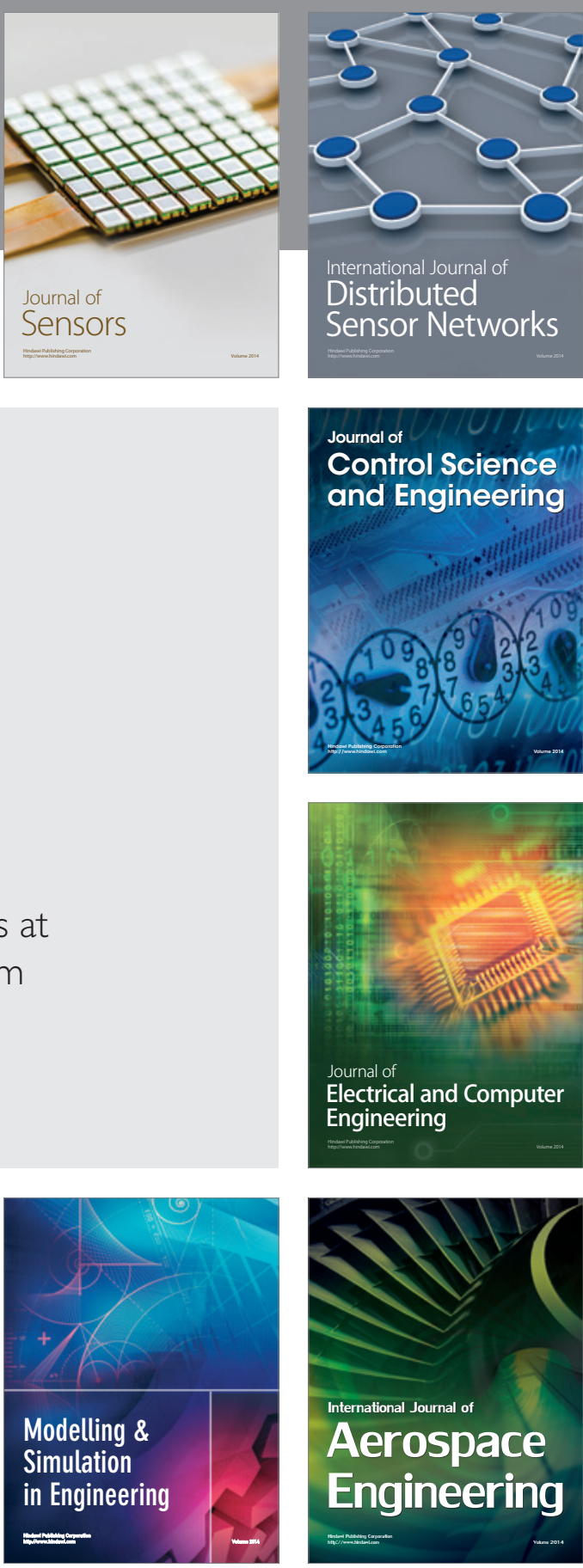

International Journal of

Distributed

Sensor Networks

Journal of

Control Science

and Engineering
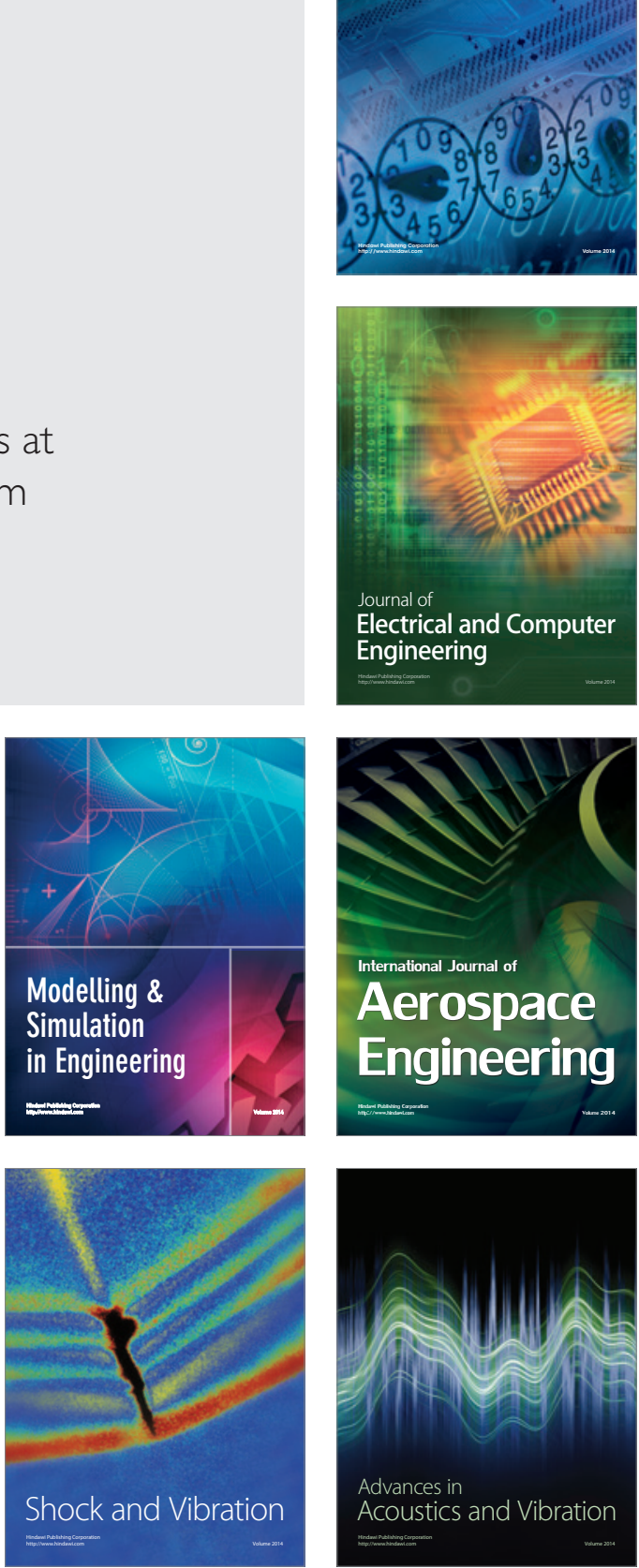